\title{
QUANTITATIVE AND QUALITATIVE EVALUATION OF F/OSS VolunteER PARTICIPATION IN DEFECT MANAGEMENT
}

\author{
Anu Gupta ${ }^{1}$, R.K. Singla ${ }^{2}$ \\ Department of Computer Science and Applications, Panjab University, Chandigarh, India \\ ${ }^{1}$ anugupta@pu.ac.in, ${ }^{2}$ rksingla@pu.ac.in
}

\begin{abstract}
Free/Open Source Software (F/OSS) is an incredible and innovative opportunity of software development in the area of software engineering. An F/OSS project evolves by receiving submissions from various sources to address different aspects of the project like bug identification, feature request, support request, translation request, source code, documentation etc. The present paper delves into a multi-case study of F/OSS projects to evaluate volunteer participation in defect management quantitatively as well as qualitatively. The relevant defect data has been retrieved from a research collaboratory. It is found that generally a small core team is surrounded by a large community of volunteers participating in defects. It is observed that defect reporting is a widely dispersed activity mostly contributed by volunteers external to core team making occasional contribution while defect resolution is concentrated among a few individuals mainly from core team making regular contribution.
\end{abstract}

\section{KEYWORDS}

Defect Management, Free Software, Open Source, Volunteer

\section{INTRODUCTION}

F/OSS is often depicted as a paradigm shift in software engineering. This may be largely due to Raymond's distinction between the cathedral and the bazaar [1]. Raymond chose the cathedral as a metaphor for the conventional software engineering approach, generally characterized by tightly coordinated, centralized teams following a rigorous development process. In contrast, the bazaar metaphor was chosen to reflect a development approach where projects were generally built by large number of volunteer contributors, communicating with each other using online tools and platforms. F/OSS development involves a transparent process where the whole source code is kept open to facilitate peer review and defect discovery [2]. Linus's Law, "Given enough eyeballs, all bugs are shallow" essentially states that given enough developers cum users looking at any particular piece of source code, any flaw in that source code will be blatantly obvious to at least one of them. Openness of source code has few key advantages for F/OSS volunteers. One advantage is the ability to test the system knowing exactly what goes on inside the software. Another advantage is the ability to fix defects without waiting for the community to catch up. A seeming advantage is the ability to adapt the system according to the organization's needs. Thus an F/OSS project evolves by receiving submissions from various sources to address different aspects of the project. The most common submissions are those of bug identification, feature request, support request, translation request and source code; others include documentation and test cases [3]. Continuous and incremental product improvement through defect finding and 
International Journal of Software Engineering \& Applications (IJSEA), Vol.3, No.2, March 2012

fixing is a development hallmark of the F/OSS paradigm and is embodied in Eric Raymond's original characterization "Release early, Release often" [1]. The idea is to get quick feedback, which can then be incorporated back into the product. Thus Defect Management System provides an effective mechanism for recording and tracking of defects as well as promotes volunteer involvement and peer review process. All the users may not have knowledge to participate in the development or code review of an F/OSS Project but such users may report bugs or request new features. They may also comment on existing defect reports or help in their removal, for example by reproducing them or supplying more information. A large amount of defect related data flows back and forth between the developers and the users of the F/OSS Projects. Hence in most of the F/OSS projects, substantial amount of defect data gets accumulated in the Defect Management Systems over the period. This valuable defect data can be analyzed from various perspectives. Moreover the availability of huge amount of information with a great variety in size, programming languages, tools, methods etc. offers the possibility of creating a comparison framework among F/OSS Projects from which knowledge and experience can be gained. In the current research, the defect data of various F/OSS Projects is analyzed to have qualitative and quantitative evaluation of volunteer participation.

The rest of the paper is organized as follows; Section II describes the organizational structure of F/OSS participants and the factors motivating their participation in F/OSS projects. Section III presents research methodology where sample selection and data extraction mechanism are briefly described. It further highlights the quantitative results. Section IV discusses the results obtained. Finally, Section V concludes and provides directions for future work.

\section{VOLUNTEER PARTICIPATION IN F/OSS PROJECTS}

The set of people that contribute code to a specific F/OSS Project is generally composed of those who are also users of the code produced. This means that F/OSS developers are a subset of the F/OSS user community [4]. The F/OSS community may be divided as shown in Figure 1.

These divisions are informal and the same developer may play different roles at different times during the lifecycle of an F/OSS Project. As shown in Figure 1, an F/OSS Project generally has a core team of few dedicated developers surrounded by a larger ring of few hundred interested collaborators who perform field testing and further surrounded by thousands or tens of thousands of users who may only be using the project [4].

However some users may eventually migrate from the outer ring to the inner rings. Some of the potential users might provide feedback and contribute to the development. Contributions can be in form of bug reports, feature requests, patch submissions or miscellaneous [5]. Most contributions will contain some sort of user insight which the development team might find useful. However, some of the suggestions may not be valid, thus rejected and not being incorporated in the F/OSS Project. The important point is that F/OSS makes it possible for an aspiring and technically capable software developer to play a larger role through continual contributions. 


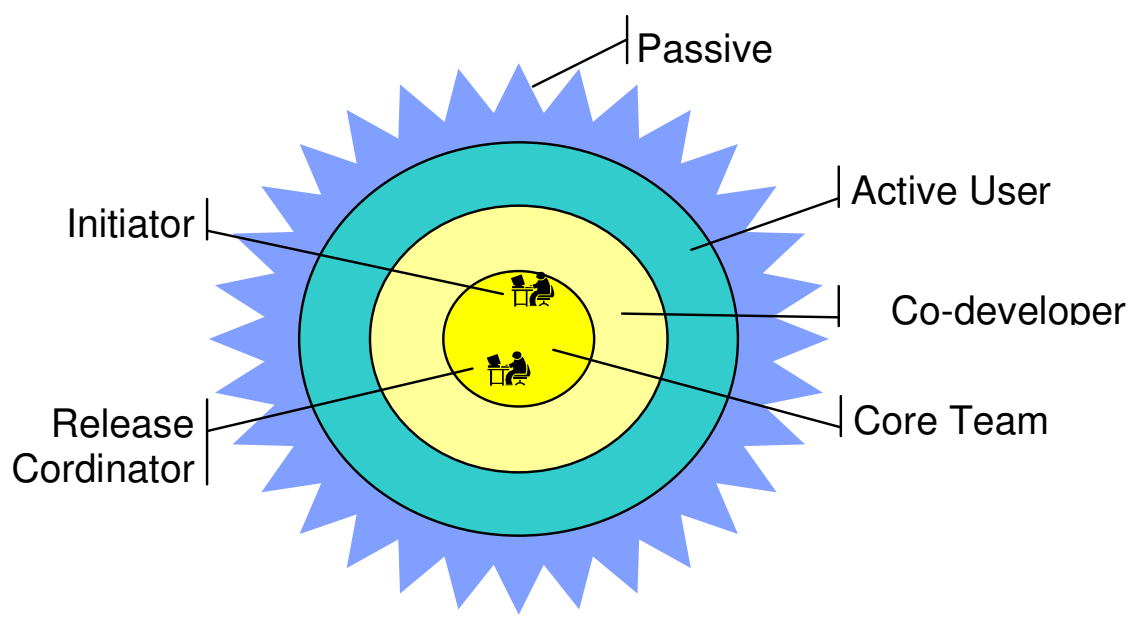

Figure 1. F/OSS Development Team Structure [4]

\subsection{Driving Factors for F/OSS Volunteer Participation}

There are several driving factors which motivate participation in F/OSS development:

- Need For Product:

Participating in order to create, customize or improve a product or feature which they require for their personal need [1], [6], [7].

- Enjoyment, Desire to Create and Improve:

Participating because one enjoys it; finds creating or improving software interesting [8].

- Reputation and Status Within the Community:

Participating in order to build or maintain reputation or status within the community [1], [9].

- Affiliation:

Participating in order to socialize or spend time with like-minded individuals [1].

- Values and Ideology:

Participating to promote specific ideals e.g. the free software philosophy [1], [8], [10].

- Learning and Career Concerns:

Participating to improve one's skills, with the belief that such improvement will lead to a better job or promotion [1], [9], [11], [12].

\section{RELATED WORK}

Several studies have also been conducted which make use of historical data of F/OSS projects. A study of popular Apache web server and Mozilla web browser quantified aspects of developer participation, core team size etc. by using e-mail archives of source code change history and defect reports [13]. Another study analyzed the temporal changes among various F/OSS projects and discussed the distribution of defects among various categories on the basis of statistics provided by SourceForge [14]. A study analyzed the debugging process of nine popular F/OSS 
International Journal of Software Engineering \& Applications (IJSEA), Vol.3, No.2, March 2012

Projects and highlighted four types of bug fixing processes that can be distinguished by considering temporal continuity and efficiency dimensions [15]. A number of statistical analyses have been recorded about the F/OSS Project Debian to make observations on the effectiveness of the F/OSS development process used by projects such as Debian [16]. Another study has investigated the coordination practices adopted within four F/OSS development teams focusing particularly on bug fixing process and confirmed the validity of Raymond's Bazaar metaphor for bug fixing process [17]. Various methods have also been developed that allow automated analyses such as a counter for physical source lines of code and tools to evaluate and interpret CVS and change log data [18] [19]. Moreover, some quantitative analyses have been published, such as one about GNOME [20] and one examining the code quality of various projects [21].

Even though there are number of qualitative and quantitative studies about F/OSS, little attention has been paid to the rich information stored in Defect Management System of F/OSS Projects. It is also found that some very successful projects have caught the attention of researchers generally. Raymond suggested that the high quality and success of F/OSS is connected to user involvement and peer review [1]. A Defect Management System effectively extends the user involvement and peer review process. All users may not have the knowledge to participate in the development or code review of an F/OSS Project but such users can report bugs or request new features. They may also comment on existing defect reports or help in their removal, for example by reproducing them or supplying more information. The importance of user involvement has greatly been emphasized [11]. It has also been found that a rich community of user-to-user assistance provides technical help and support to each other [7]. Volunteers can steer the F/OSS Project in a particular direction through emphasis on certain feature requests and can work with other developers to remove defects, thereby increasing the quality of the F/OSS product. There is a considerable requirement of effort to establish methods specifically focusing upon extensibility and maintainability which can help potential users to choose the most appropriate F/OSS Product in a much easier, faster and more efficient manner.

\section{RESEARCH METHODOLOGY}

The current study aims to evaluate the F/OSS volunteer participation in defect management on the basis of two perspectives i.e. participation in defect reporting and participation in defect resolution.

\subsection{Project Selection and Data Collection}

In the current study, F/OSS Projects are selected from SourceForge, a centralized place for F/OSS developers to host their projects [22]. It is the world's largest F/OSS Projects repository with more than 230,000 F/OSS projects and over 2 million registered users. It provides some of the best empirical data on F/OSS research. A single source is chosen to select projects in order to control for differences in available tools and project visibility. In spite of large number of projects hosted, only a small proportion of these projects are actually active. Also many of the F/OSS Projects either do not use or do not allow public access to Defect Management System. Hence those projects are considered for which defect related data is publicly accessible and is being maintained completely at SourceForge. Another criterion used for selection of projects is the project development stage (1-6 where 1 is the planning and 6 is a mature stage). A cut-off of 5 is chosen which indicates that the selected projects are at similar stage of development and are not in the early stage of development lifecycle.

A total of 20 projects are selected which constitute a diverse mix of project size, team size, nature of application and targeted end user type. Selection of limited number of projects has helped to carry out in-depth study. For all the selected F/OSS projects, detailed defect data is downloaded from SourceForge Research Data Archive (SRDA) for the period starting from their respective 
International Journal of Software Engineering \& Applications (IJSEA), Vol.3, No.2, March 2012

Registration Date to October 2008 [23]. The defect data is downloaded on the basis of unique Project ID assigned to each project at SourceForge and is stored in the local repository (mySQL) aggregating more than 60,000 defect records. Further the Defect Analysis and Reporting Tool (DART) is used to carry out exhaustive analysis of defect data and generate variety of textual/graphical reports.

\subsection{Quantitative Results}

The detailed results obtained are being presented with the help of statistics and various graphs in the following subsections.

\subsubsection{Volunteer Participation in Defect Reporting}

Raymond, in his seminal work, describes the importance of users [1]. Every project needs a constituency of users who use the project, want the project to work and are sufficiently committed to make at least some efforts towards improving it. The consistent involvement of such volunteers makes the discovery and elimination of defects easier and quicker [24].

It is seen that all the projects have quite large number of downloads. These downloads could be made by existing users for a new version release or by potential users in anticipation of use. There could be circumstances that a project is either repeatedly downloaded or downloaded but never used. Assuming that only $10 \%$ of total downloads are actually being used, the graphs have been plotted to compare the total downloads, $10 \%$ of total downloads and number of distinct participating users. Such graphs for some of the F/OSS projects are shown in Figure 2 and 3. It is observed that even in comparison to $10 \%$ of total downloads; the number of contributing users for defects is scanty.

A graph has also been plotted to compare average number of volunteers participating in defects with average core team size for all the selected F/OSS Projects (Figure 4). It is found that generally a small team is surrounded by a large community of volunteers participating in defects. In order to participate in a project, a volunteer is supposed to get registered on the project web site. But many volunteers also participate through guest login referred as anonymous volunteer. A graph (Figure 5) has been plotted to compare the participation of anonymous volunteers with other registered volunteers. It is found that quite large contribution is from anonymous volunteers i.e. $30 \%$ on an average.

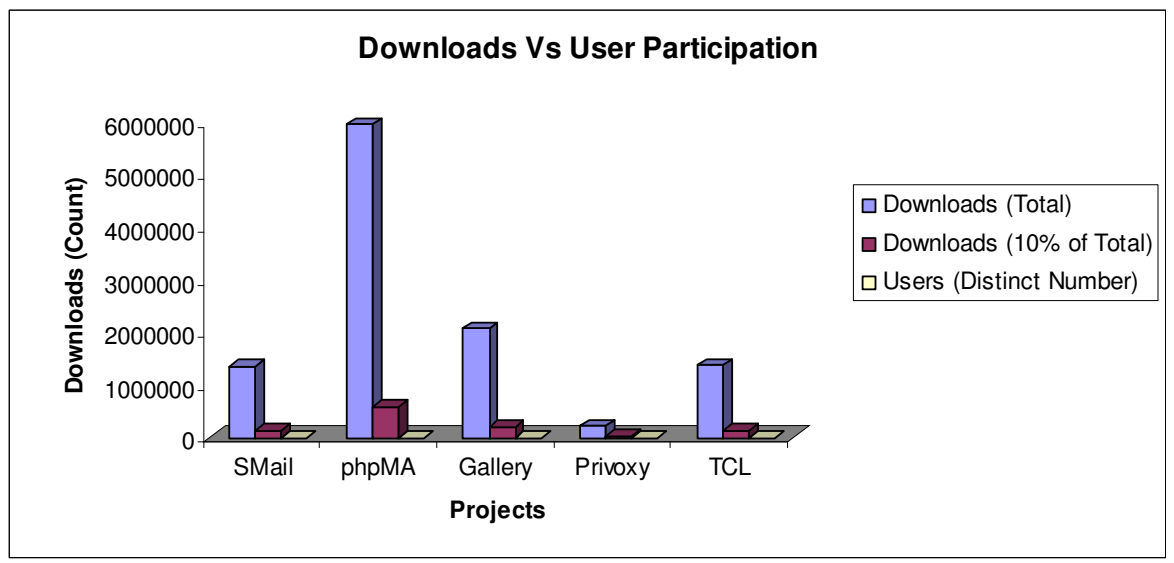

Figure 2. Volunteer Participation in Defect Reporting in F/OSS Projects 


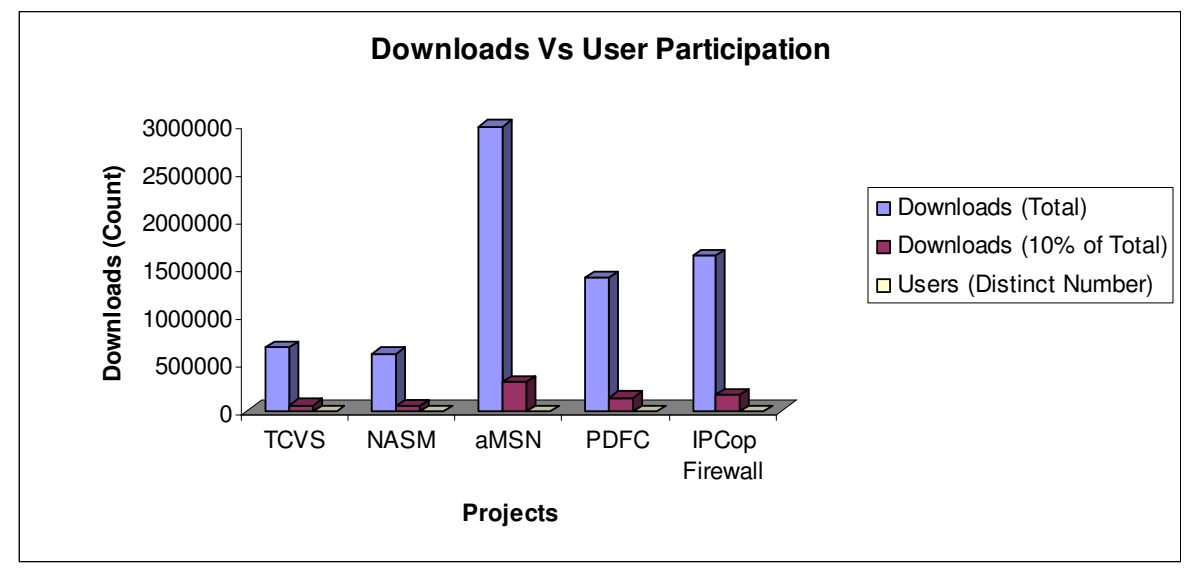

Figure 3. Volunteer Participation in Defect Reporting in F/OSS Projects

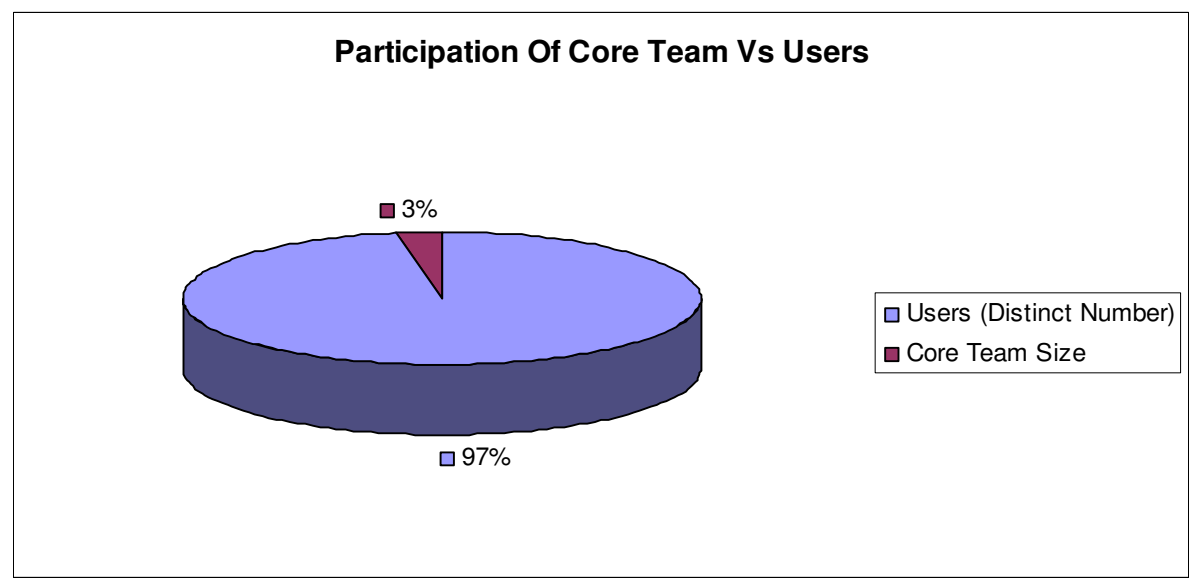

Figure 4. Core Team Vs Other Volunteers Participation in Defect Reporting

Figure 6 and Table 1 highlight the proportion of defects reports submitted by core team and the participants external to core team. In most of the selected F/OSS Projects, it is found that the major proportion of defect reports is contributed by volunteers external to core team.

To determine the regularity of participating volunteers in defect reporting, the participating volunteers have been distributed on the basis of number of defect reports submitted by them (Once, Twice, Thrice, 4 to 10 times, More than 10 times). Figure 7 and 8 show the graphs for the same. Looking at the percentage of volunteers in each category, it has been observed that the most of the registered volunteers are not participating regularly. A very small percentage of volunteers are submitting defect reports more than 10 times.

Table 2 highlights descriptive statistics for some of the selected projects which are computed on the basis of number of defects reported by each registered volunteer. Average number of defects being reported ranges from 1.49 to 3 defects per volunteer in the above mentioned projects. In all the above projects, high positive values of skewness indicate that distributions are skewed positively or to the right which refers that quite large numbers of people are reporting defects 
International Journal of Software Engineering \& Applications (IJSEA), Vol.3, No.2, March 2012

once, twice or thrice. Looking at the average of 20 projects, about $91 \%$ of the volunteers are contributing once, twice or thrice. A very few volunteers are regular users (Figure 9).

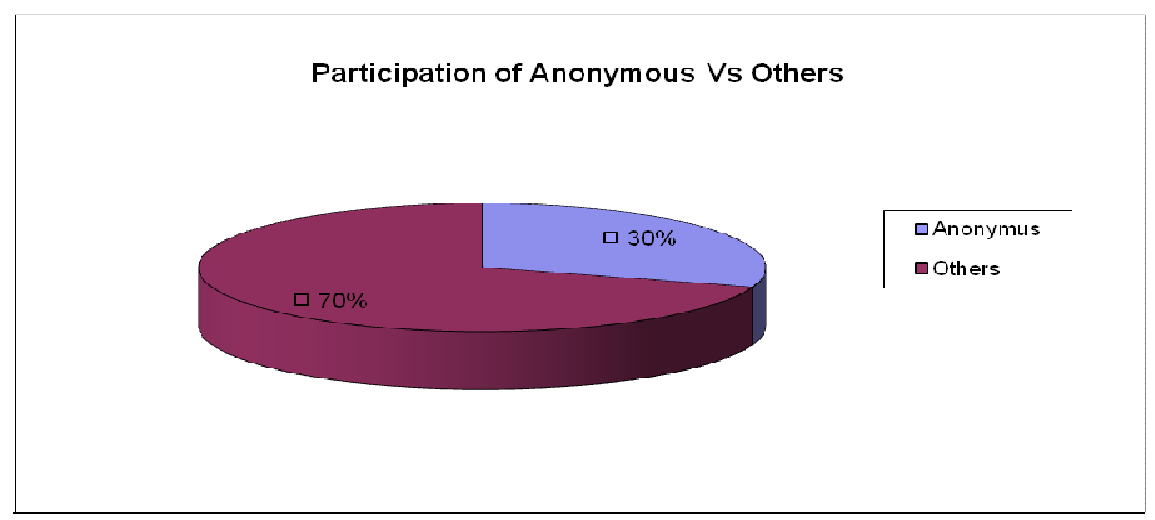

Figure 5. Anonymous Vs Registered Volunteers Participation in Defect Reporting

Table 1. Percentage Contribution in Defect Reporting

\begin{tabular}{|l|r|r|r|r|}
\hline Project & Core Team & Anonymous & \multicolumn{1}{c|}{ Others } & \multicolumn{1}{c|}{ Total } \\
\hline SMail & 1.50 & 42.49 & 56.01 & 100.00 \\
\hline phpMA & 8.33 & 19.54 & 72.13 & 100.00 \\
\hline Gallery & 9.60 & 22.19 & 68.21 & 100.00 \\
\hline Privoxy & 5.64 & 71.68 & 22.68 & 100.00 \\
\hline TCL & 33.52 & 41.08 & 25.41 & 100.00 \\
\hline Webmin & 0.10 & 60.93 & 38.97 & 100.00 \\
\hline HSQLDB & 11.00 & 31.40 & 57.60 & 100.00 \\
\hline NSIS & 8.04 & 39.82 & 52.14 & 100.00 \\
\hline TCVS & 14.34 & 0.00 & 85.66 & 100.00 \\
\hline NASM & 28.07 & 42.52 & 29.40 & 100.00 \\
\hline aMSN & 0.67 & 46.35 & 52.98 & 100.00 \\
\hline PDFC & 0.24 & 64.20 & 35.56 & 100.00 \\
\hline IPCF & 8.73 & 1.35 & 89.92 & 100.00 \\
\hline hCRM & 93.92 & 1.03 & 5.05 & 100.00 \\
\hline KeePass & 8.62 & 49.31 & 42.07 & 100.00 \\
\hline ClamWin & 0.23 & 58.18 & 41.59 & 100.00 \\
\hline Azureus & 1.32 & 7.14 & 91.53 & 100.00 \\
\hline
\end{tabular}




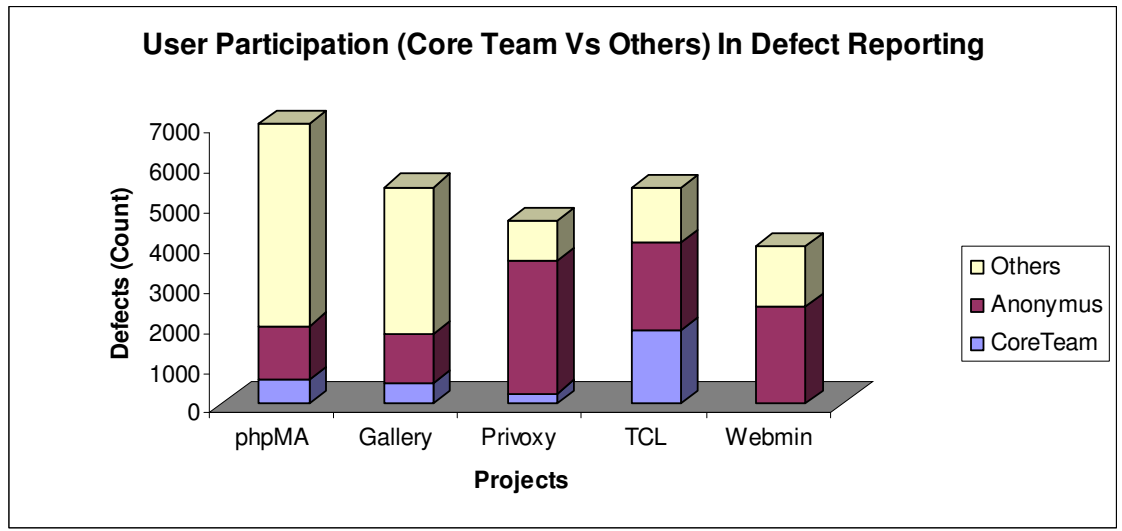

Figure 6. Contribution in Defect Reporting

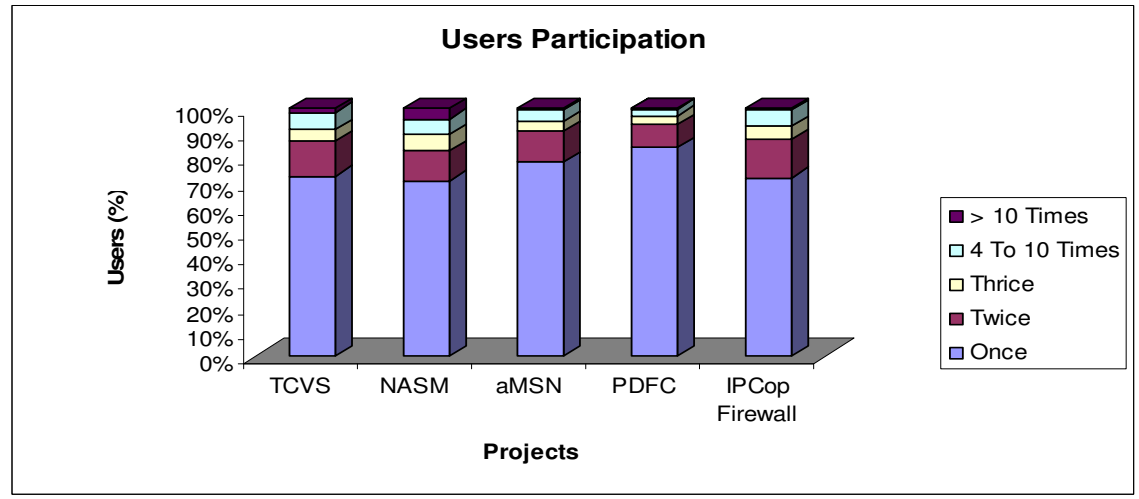

Figure 7. Volunteers Participation (Regularity) in Defect Reporting among F/OSS Projects

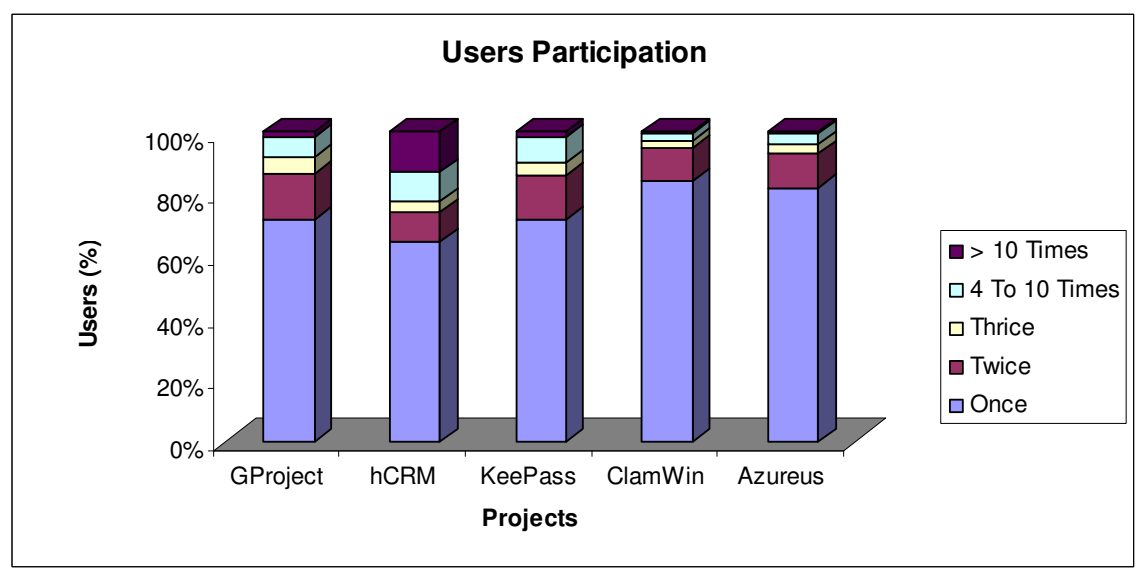

Figure 8. Volunteers Participation (Regularity) in Defect Reporting among F/OSS Projects 
International Journal of Software Engineering \& Applications (IJSEA), Vol.3, No.2, March 2012

Table 2. Descriptive Statistics on Volunteers Participation in Defect Reporting

\begin{tabular}{|l|r|r|r|r|r|}
\hline & SquirrelMail & php Myadmin & \multicolumn{1}{c|}{$\begin{array}{c}\text { Tortoise } \\
\text { CVS }\end{array}$} & $\begin{array}{c}\text { Netwide } \\
\text { Assembler }\end{array}$ & \multicolumn{1}{|c|}{ aMSN } \\
\hline Mean & 1.73 & 2.19 & 1.97 & 3.01 & 1.49 \\
\hline $\begin{array}{l}\text { Standard } \\
\text { Deviation }\end{array}$ & 3.26 & 7.40 & 4.34 & 12.43 & 1.57 \\
\hline Skewness & 18.49 & 15.15 & 12.37 & 10.22 & 7.83 \\
\hline $\begin{array}{l}\text { Sum of } \\
\text { Reported } \\
\text { Defects }\end{array}$ & 2496 & 5622 & 2162 & 346 & 1593 \\
\hline $\begin{array}{l}\text { Count of } \\
\text { Registered } \\
\text { Volunteers }\end{array}$ & 1446 & 2568 & 1101 & 115 & 1070 \\
\hline
\end{tabular}

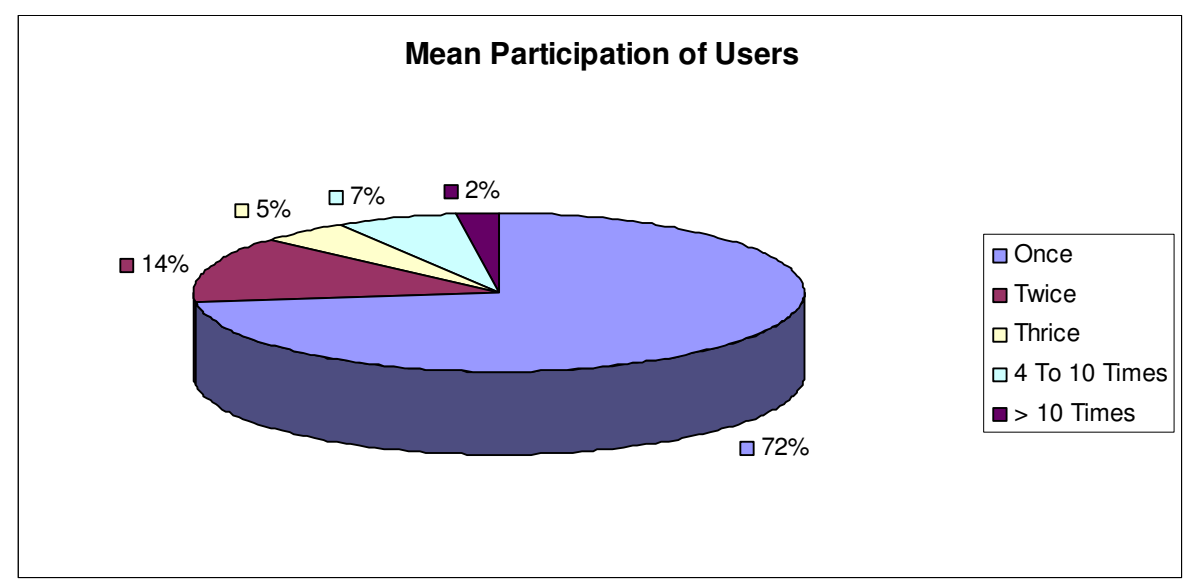

Figure 9. Mean Volunteers Participation (Regularity) in Defect Reporting

\subsubsection{Volunteer Participation in Defect Resolution}

Core Team and volunteers other than core team are free to participate in defect resolutions. So analysis is carried out among selected projects to observe the proportion of defects resolved by core team, anonymous and others (Figure 10 and Table 3). It is found that in several projects, major proportions of defects are resolved by core team.

Further to determine the regularity of participants in defect resolution, the participating volunteers have been distributed on the basis of number of defects resolved by them (Once, Twice, Thrice, 4 to 10 times, More than 10 times). Figure 11 and 12 show the graphs for the same. Looking at the percentage of volunteers in each category, it has been observed that most of the defects are resolved by participants contributing frequently (4 to 10 times or More than 10 times).

Table 4 highlights descriptive statistics on participation of registered volunteers in defect resolution for some of the selected projects. As compared to large number of volunteers participating in defect reporting, defect resolution involves participation from lesser number of volunteers with average number of defects resolved ranging from 61.18 to 300.82 per volunteer in the above mentioned projects. 
International Journal of Software Engineering \& Applications (IJSEA), Vol.3, No.2, March 2012

In all the above projects, positive values of skewness near to 3 indicate that defect resolution is concentrated among quite small number of registered volunteers making heavy contribution. Figure 13 shows that overall $70 \%$ defects are resolved by regular participants.

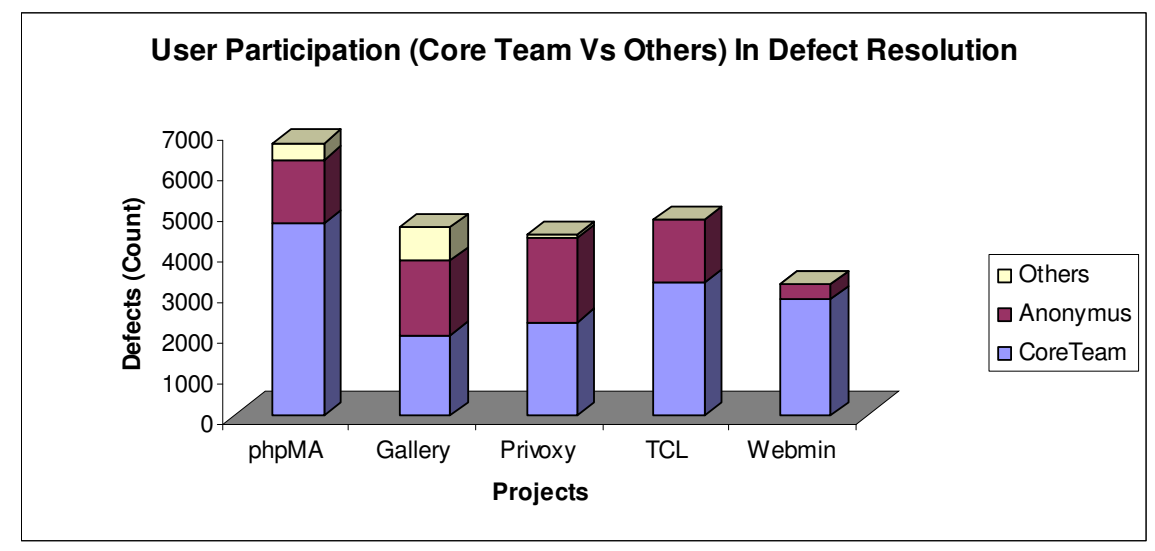

Figure 10. Contribution in Defect Resolution

Table 3. Percentage Contribution in Defect Resolution (Volunteer Type Wise)

\begin{tabular}{|l|c|c|c|c|}
\hline Project & Core Team & Anonymous & Others & Total \\
\hline phpMA & 70.47 & 23.41 & 6.13 & 100.00 \\
\hline Gallery & 42.28 & 39.60 & 18.12 & 100.00 \\
\hline Privoxy & 51.31 & 46.82 & 1.87 & 100.00 \\
\hline TCL & 67.95 & 31.86 & 0.19 & 100.00 \\
\hline SMail & 12.09 & 71.65 & 16.26 & 100.00 \\
\hline Webmin & 88.73 & 11.27 & 0.00 & 100.00 \\
\hline HSQLDB & 86.04 & 13.96 & 0.00 & 100.00 \\
\hline NSIS & 90.23 & 9.18 & 0.59 & 100.00 \\
\hline TCVS & 54.63 & 43.22 & 2.14 & 100.00 \\
\hline NASM & 6.96 & 92.83 & 0.21 & 100.00 \\
\hline aMSN & 24.51 & 63.98 & 11.51 & 100.00 \\
\hline PDFC & 0.92 & 99.08 & 0.00 & 100.00 \\
\hline IPCF & 48.96 & 51.04 & 0.00 & 100.00 \\
\hline GProject & 31.48 & 66.21 & 2.31 & 100.00 \\
\hline hCRM & 0.85 & 97.46 & 1.69 & 100.00 \\
\hline KeePass & 0.75 & 99.25 & 0.00 & 100.00 \\
\hline ClamWin & 39.90 & 60.10 & 0.00 & 100.00 \\
\hline Azureus & 73.99 & 24.77 & 1.24 & 100.00 \\
\hline
\end{tabular}


International Journal of Software Engineering \& Applications (IJSEA), Vol.3, No.2, March 2012

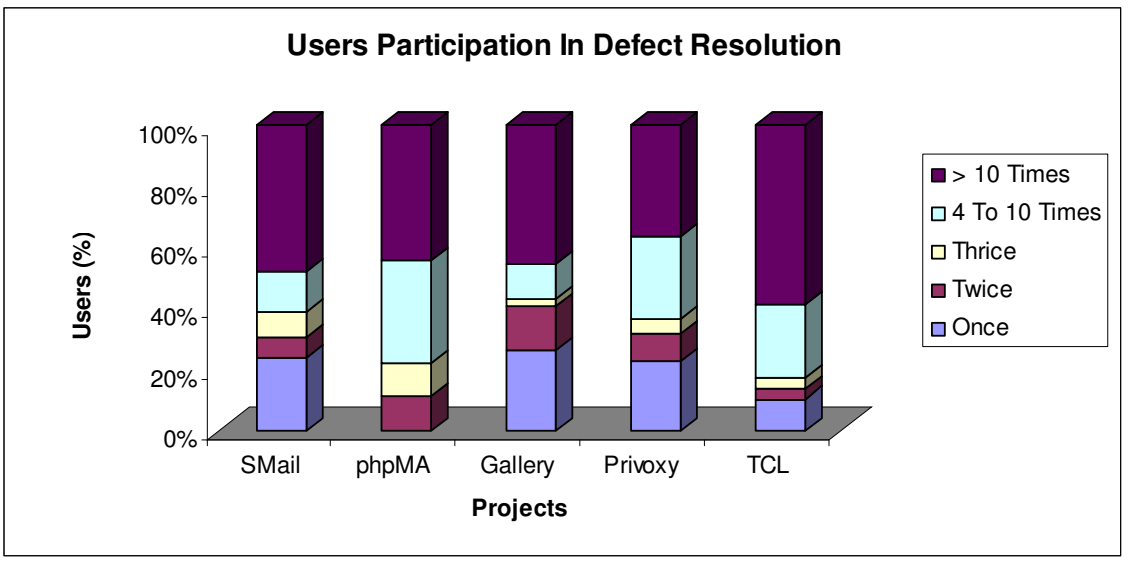

Figure 11. Volunteers Participation (Regularity) in Defect Resolution of F/OSS Projects

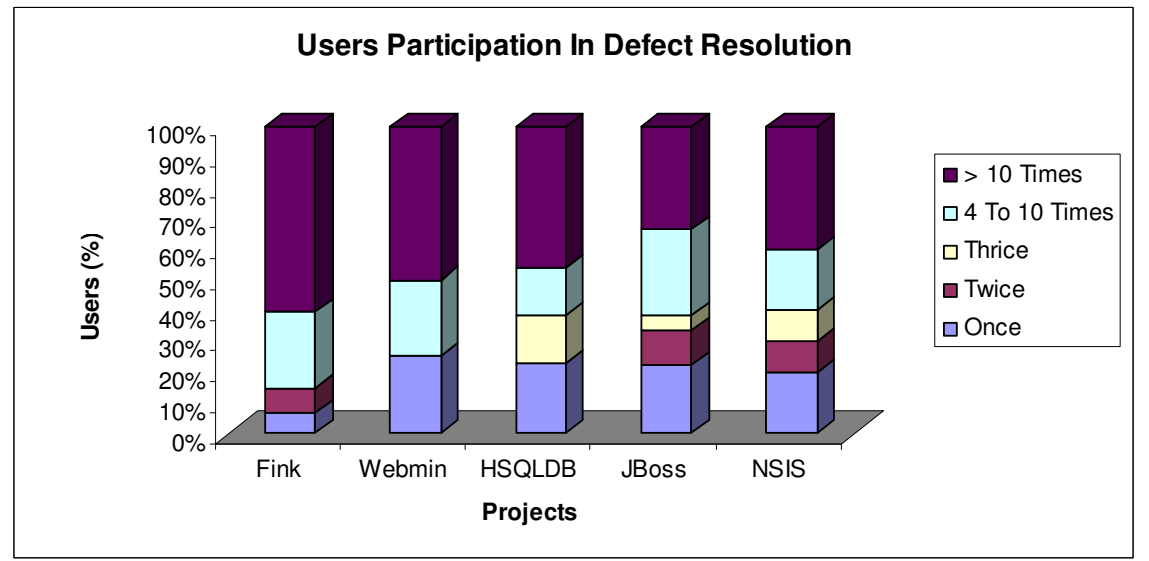

Figure 12. Volunteers Participation (Regularity) in Defect Resolution of F/OSS Projects (6-10)

Table 4. Descriptive Statistics of Registered Volunteers Participation in Defect Resolution

\begin{tabular}{|l|r|r|r|r|r|}
\hline & phpMyadmin & \multicolumn{1}{c|}{ TCL } & \multicolumn{1}{c|}{ Fink } & \multicolumn{1}{c|}{ NSIS } & \multicolumn{1}{c|}{ HSQLDatabase } \\
\hline Mean & 300.82 & 117.07 & 61.18 & 137.44 & 82.17 \\
\hline $\begin{array}{l}\text { Standard } \\
\text { Deviation }\end{array}$ & 626.08 & 185.33 & 109.90 & 363.98 & 173.07 \\
\hline Skewness & 3.13 & 2.05 & 2.78 & 2.95 & \\
\hline $\begin{array}{l}\text { Sum of } \\
\text { Defects } \\
\text { Resolved }\end{array}$ & 5114 & 3278 & 3671 & 1237 & 986 \\
\hline $\begin{array}{l}\text { Count of } \\
\text { Registered } \\
\text { Volunteers }\end{array}$ & 17 & & & & \\
\hline
\end{tabular}




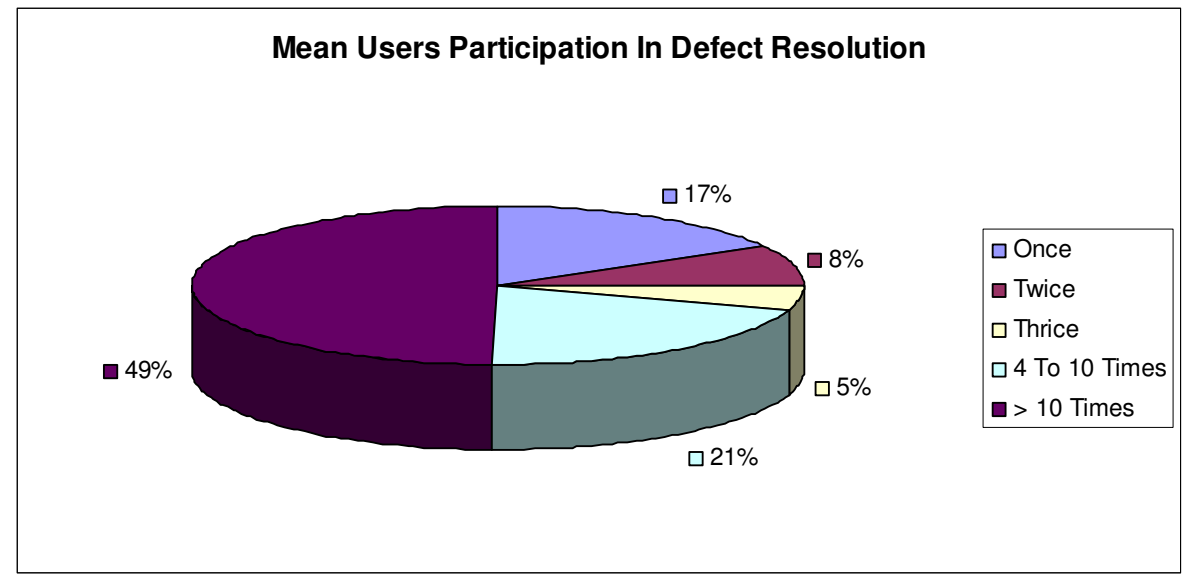

Figure 13. Mean Volunteers Participation (Regularity) in Defect Resolution

\section{DISCUSSION}

The consistent involvement of global community of volunteers makes the discovery and elimination of defects easier as well as quicker [1]. It is seen that all the projects have quite large number of downloads. These downloads could be made by existing users for a new version release or prospective users may download it in anticipation of use. There could be circumstances that a project is either repeatedly downloaded or downloaded but never used. It is observed that in comparison to total number of downloads; the number of volunteers contributing for defects is quite low. But in comparison to core team size, this figure seems to be quite significant. It is also found that about one third of total defects are made by volunteers who are not registered on the SourceForge. There is no specific reason for anonymous participation but it seems that some volunteers either do not want to disclose their identity or do not want to follow the lengthy procedure of registration. So it is required the volunteer registration procedure should be simplified as well as personal information should be protected from public accessibility. Results about number of times each registered volunteer is participating are quite astonishing. It has been observed that even the most of registered volunteers are not participating regularly. Looking at the average of 20 projects, most of the volunteers are participating once, twice or thrice. A very few volunteers are participating more than three times but their active participation is contributing quite large number of defect reports. Although no significant relationship could be observed between irregular participation in defect reporting and other defect parameters but it seems that one of the probable reasons is that F/OSS volunteers report defects while evaluating the F/OSS product for future use but never start using it or discontinue the usage after some time. In certain cases, the volunteers may be discouraged as they may not be able to get the resolution as per their expectation with in the desired time period.

Core team and volunteers other than core team are free to participate in defect resolutions. So analysis is carried out among all the selected projects to observe the proportion of defects resolved by core team, anonymous and others. It is found that in most of the selected projects, major proportion of defects are resolved by core team contrary to the defects reporting scenario where major contribution is from volunteers other than core team. Further to determine the 
International Journal of Software Engineering \& Applications (IJSEA), Vol.3, No.2, March 2012

regularity of registered participants in defect resolution, the participating volunteers have been distributed on the basis of number of defect reports resolved by them and it has been observed that overall $70 \%$ of the defects are resolved by participants contributing frequently (4 to 10 times or more than 10 times). Hence in defect resolution the major contribution is made by members of core team who participate quite regularly.

\section{CONCLUSION}

The research findings contribute to an understanding of F/OSS development process and provide empirical evidences on volunteer participation in defect reporting and defect resolution. An analysis of more than 60,000 defect reports associated with 20 F/OSS Projects reveals that many important insights can be gained through the analysis of defect data that has been recorded over the years. Generally an F/OSS project is developed by a small team of core developers which is surrounded by a community consisting of large number of globally distributed users. Not every F/OSS user has the technical skills to take part in code review or to carry out development. However, these users can contribute to the project by reporting bugs or by suggesting new features. It is found that size of this globally distributed community is very small in comparison to total number of downloads for the projects. The defect management efforts are not equally distributed among F/OSS community. Defect reporting is a widely dispersed type of action mostly contributed by volunteers external to core team while defect resolution is concentrated among a few individuals mainly from core team. Generally, the most active volunteers in the projects carry out most of the tasks while others contribute only once or twice. Although F/OSS projects are benefited by active participation of globally distributed community in defect reporting but some initiatives need to be taken to encourage their participation in defect resolution also.

\section{ACKNOWLEDGMENTS}

We are thankful to the University of Notre Dame for providing access to Sourceforge Research Data Archive (SRDA) for retrieving data on F/OSS projects.

\section{REFERENCES}

[1] Eric S. Raymond, "The Cathedral and the Bazaar", First Monday, vol. 3, no. 3, 1998.

[2] Joseph Feller, Brian Fitzgerald, Scott A. Hissam and Karim R. Lakhani, Perspectives on Free and Open Source Software, 2005, The MIT Press.

[3] Anthony Senyard and Martin Michlmayr, "How to Have a Successful Free Software Project", Proceedings of 11th Asia-Pacific Software Engineering Conference (APSEC'04), November 2004, Busan, Korea, pp. $84-91$.

[4] Kevin Crowston and James Howison, "The Social Structure of Free and Open Source Software Development", First Monday, vol. 10, no. 2, 2005.

[5] Cristina Gacek and Budi Arief, "The Many Meanings of Open Source”, IEEE Software, vol. 21, no. 1, 2004, pp. 34-40.

[6] Jennifer W. Kuan, "Open Source Software As Consumer Integration into Production”, 2001. Available: http://ssrn.com/abstract=259648

[7] Nikolaus Frank and Eric Von Hippel, "Satisfying Heterogeneous User Needs via Innovation Toolkits: The Case of Apache Security Software", Research Policy, vol. 32, no. 7, 2003, pp. 1199-1215.

[8] Ron Goldman and Richard P. Gabriel, Innovation Happens Elsewhere - Open Source as Business Strategy, Boston: Morgan Kaufmann, 2005. 
International Journal of Software Engineering \& Applications (IJSEA), Vol.3, No.2, March 2012

[9] Karim R. Lakhani and Eric Von Hippel, "How Open Source Software Works:"Free” User-to-User Assistance", MIT Sloan Working Paper, No. 4117-00,2000. Available: ttp://opensource.mit.edu/papers/lakhanivonhippelusersupport.pdf

[10] Richard Stallman, "Why software should be free", 1992. Available: http://www.gnu.org/philosophy/shouldbefree.html

[11] Jean Tirole and Josh Lerner, "The Simple Economics of Open Source", Journal of Industrial Economics, vol. 52, 2002, pp. 197-234

[12] Jeffery A. Roberts, I. Hann, Sandra A. Slaughter, "Understanding the Motivations, Participation and Performance of Open Source Software Developers: A Longitudinal Study of the Apache Projects", Management Science, vol. 52, no. 7, 2006, pp. 984-999.

[13] Audris Mockus, Roy Fielding and James D. Herbsleb, "Two Case Studies of Open Source Software Development: Apache and Mozilla" ACM Transactions on Software Engineering and Methodology, Vol. 11, No.3, 2002, pp 309-346.

[14] Dawid Weiss, "A Large Crawl and Quantitative Analysis Of Open Source Projects Hosted On Sourceforge", Research Report ra-001/05(2005), Institute of Computing Science, Pozna University of Technology, Poland. http://www.cs.put.poznan.pl/dweiss/xml/publications/index.xml

[15] Chiara Francalanci and Francesco Merlo, "Empirical Analysis of the Bug Fixing Process in Open Source Projects”, Open Source Development, Communities and Quality, Springer Boston, Vol. 275, 2008, pp 187-196.

[16] Martin Michlmayr and Anthony Senyard, "A Statistical Analysis of Defects in Debian and Strategies for Improving Quality in Free Software Projects", The Economics of Open Source Software Development, Elsevier B.V., 2006, pp 131-148.

[17] Kevin Crowston and Barbara Scozzi, "Bug Fixing Practices within Free/Libre Open Source Software Development Teams”, Journal of Database Management, Vol. 19, No. 2, 2008, pp 1-30.

[18] David A. Wheeler, "Estimating Linux's Size Version 1.04", May 2001. http://www.dwheeler.com/sloc/ [Online]

[19] Daniel German and Audris Mockus, " Automating the Measurement of Open Source Projects", Proceedings of the 3rd Workshop on Open Source Software Engineering, International Conference on Software Engineering, May 2003, Portland, Oregon, USA.

[20] Stefan Koch, "Effort Modeling and Programmer Participation in Open Source Software Projects ", Information Economics and Policy, Vol. 20, No. 4, 2008, pp 345-355.

[21] Ionic Stamelos, Lefteris Angelis, Apostolos Oikonomou and Georgios L. Bleris, "Code Quality Analysis in Open Source Software Development”, Information Systems Journal, Vol. 12, No. 1, 2002, pp 43-60.

[22] "SourceForge", Available: http://sourceforge.net/

[23] Yongqin Gao, Matthew Van Antwerp, Scott Christley and Greg Madey, "A Research Collaboratory for Open Source Software Research", Proceedings of 29th International Conference on Software Engineering + Workshops (ICSE-ICSE Workshops 2007), International Workshop on Emerging Trends in FLOSS Research and Development (FLOSS 2007), May 2007, Minneapolis, Minnesota, USA.

[24] Walt Scacchi, "Is Open Source Software Development Faster, Better and Cheaper than Software Engineering", 2nd ICSE Workshop on Open Source Software Engineering, May 2002, Orlando, Florida, USA. 


\section{Authors}

\section{Dr. Anu Gupta}

Dr. Anu Gupta has been working as Assistant Professor in Computer Science and Applications at Panjab University, Chandigarh since July 1998. She has also held the position of Chairperson, Department of Computer Science \& Applications, Panjab University, Chandigarh (Feb. 2008- Jan. 2011) .She was awarded University medal for securing first position in M.C.A. at Punjabi University, Patiala, Punjab in the year 1997. She has the experience of working on several platforms using a variety of development tools and application packages. She has completed the Doctor of Philosophy Degree from Panjab University in the area of Free/Open Source Software. Her research interests include Networking,

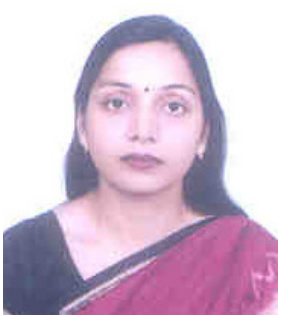
Multimedia Technologies, E-Commerce and Software Engineering. She is a life-member of 'Computer Society of India' and 'Indian Academy of Science'. She has published several research papers in various journals and conferences.

\section{Dr. R.K. Singla}

Dr. R.K. Singla has been Professor of Computer Science and Applications at Panjab University, Chandigarh since July 2004 where he has been a faculty member since 1988. He held many IT-related positions including Chairman, Department of Computer Science \& Applications; Coordinator, TIFAC-DST; Project Leader; and Programmer/Analyst. His experience covers large mainframes, minicomputers, microcomputers, and several types of specialized equipment. He has programmed in over a dozen languages including Visual Basic, C, C++, COBOL, FORTRAN, Pascal, several versions of assembly, and machine language. He has the experience of working on several platforms including VAX-VMS, SUN-Solaris, HP-UX etc.

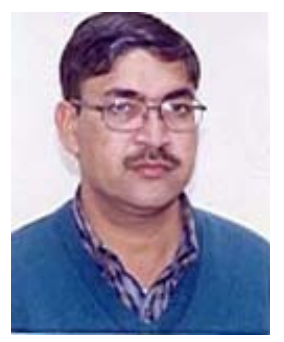
using a variety of development tools and application packages. He obtained the Doctor of Philosophy Degree in Faculty of Science from Panjab University. His research interests include scientific computing, linux networking, mobile computing, open source software and software cost estimation. He is also a member of editorial board of 'Panjab University Research Journal (Science)-New Series'. He is a lifemember of 'Computer Society of India'. He has published 35 research papers in various journals and conferences. 